\title{
Making adaptive governance work in biodiversity conservation: lessons in invasive alien aquatic plant management in Lake Biwa, Japan
}

\author{
$\underline{\text { Kentaro Miyanaga }}^{1}$ and $\underline{K a t s u k i}$ Nakai $^{2}$
}

\begin{abstract}
Invasive alien species are a serious threat to freshwater ecosystems and overall biodiversity. Although invasive alien species management in the form of environmental governance has often been practiced under an adaptive governance scheme, prevailing theoretical and practical difficulties must be solved to enhance policy effectiveness and outcomes. Our objective was to clarify how it is possible to make adaptive governance work in biodiversity conservation, especially invasive alien species management in freshwater ecosystems. To fulfill this objective, we investigated two analytical concepts - invasion management and adaptive governance-and studied a case of invasive alien aquatic plant management in Lake Biwa, Japan. The conclusion of our analysis and the lessons learned can be summarized as the following three points: First, whether learning processes are properly equipped by local environmental governance is critical for adaptive governance. We provide insights into three aspects of learning: the system where scientific knowledge is produced and shared for policy preparation, implementation, and evaluation; where social learning and processes that support social learning occur; and where a process of organizational learning occurs. Second, we discuss the role and function of government in adaptive governance, which indicates that interactive governance is possible even when a government initiates a governing process, and that an interactive governing structure would be fundamental for addressing social-ecological complexities and uncertainties. Third, the transition from symptomatic treatments toward precautionary actions for invasive alien species, which is essential for policy effectiveness and outcomes, can be fostered by an interactive governing structure. In addition, organizational learning can induce the transition, through which the competency trap caused by conformity bias in invasive alien species management could be avoided.
\end{abstract}

Key Words: adaptive governance; biodiversity conservation; environmental governance; invasive alien species; Lake Biwa; Ludwigia grandiflora

\section{INTRODUCTION}

Freshwater ecosystems comprise a small fraction of the Earth's surface area, are particularly valuable among the types of ecosystems, and are one of the most severely degraded ecosystems. Notably, biodiversity is key to maintaining affordances provided by freshwater ecosystems.

Invasive alien species (IAS) ${ }^{[1]}$ are a serious threat to freshwater ecosystems and biodiversity, and must be addressed (e.g., Nakai 2009, Riccardi and Maclsaac 2011, Francis 2012). For example, 23 species of the "100 of the World's Worst Invasive Alien Species," prepared by the International Union for Conservation of Nature, are related to freshwater ecosystems. This situation can be partly explained by the following: the physical distance between human beings and freshwater ecosystems must be close because water is essential for human beings and society, and control efficiency in a water area is usually lower than that in a land area.

Further, IAS cause substantial spatial and temporal threats to overall biodiversity (and ecosystem services) because they often alter ecological functions and processes, harm ecological resilience, and trigger regime shifts (Chaffin et al. 2016). To make matters worse, in an interim assessment of the progress of Aichi Targets, the Global Biodiversity Outlook 4 emphasized that "the efforts taken thus far are still overwhelmed by the global rate of alien species introductions, which shows no sign of slowing" (Secretariat of the Convention on Biological Diversity 2014:72).

Thus, to conserve freshwater ecosystems and biodiversity, how should IAS management be developed? To answer this question, we focus on three themes, all of which we explore theoretically and empirically.

The first theme is that environmental governance has sometimes been practiced in local IAS management. Although environmental governance has no consistent, accepted definition (Ohno 2018), the definition we use is a "set of regulatory process, mechanisms and organizations through which political actors influence environmental actions and outcomes" (Lemos and Agrawal 2006:298), with the recognition that "governments are not, and in fact cannot be, the most important source of environmental decision-making authority" (Armitage et al. 2012:246).

The second theme is the concept of invasion management (e.g., Simberloff et al. 2013). This concept has been investigated mainly in invasion ecology research, in which researchers have attempted to answer the question of how IAS problems should be addressed and can play a key role in effective environmental governance in IAS management.

The third theme is adaptive governance (e.g., Dietz et al. 2003, Brunner et al. 2005, Folke et al. 2005). It is also a key analytical concept for exploring how environmental governance can (and should) implement IAS management and biodiversity conservation (Chaffin et al. 2016). Adaptive governance relates mostly to "a range of interactions between actors, networks, organizations, and institutions emerging in pursuit of a desired state for social-ecological systems" (Chaffin et al. 2014).

Each of the three themes has unresolved problems or unanswered questions. Regarding the first theme, the relationship between 
environmental governance and biodiversity conservation is not obvious. For example, although IAS problems have often been discussed in terms of public involvement (e.g., Davis et al. 2018, Novoa et al. 2018, Shackleton et al. 2019), they have been unsatisfactorily investigated in environmental governance studies.

Regarding the second theme, although the concept of invasion management has been practiced, many practitioners have had difficulty, especially in precautionary actions against IAS problems (e.g., Riccardi et al. 2011, Kamigawara 2016). Notably, the Global Biodiversity Outlook 4 states, "actions tend to be concentrated on control and eradication, with relatively few examples of actions to identify, prioritize and manage the pathways of introduction" (Secretariat of the Convention on Biological Diversity 2014:71).

Regarding the third theme, the concept of adaptive governance has often had a gap between theory and practice; for example, the tendency to be optimistic about the possibility of developing common understandings, trust, and collaboration between different interests and interest groups (Cleaver and Whaley 2018).

Our objective is to clarify how to practice adaptive governance in biodiversity conservation, especially IAS management of freshwater ecosystems, which contributes to solving the aforementioned problems and answering the aforementioned questions. To fulfill this objective, we further deploy two analytical concepts - invasion management and adaptive governance - and conduct a case study of invasive alien aquatic plant management in Lake Biwa, Japan.

Lake Biwa, Japan's largest lake, in Shiga prefecture, has a surface area of $674 \mathrm{~km}^{2}$, a catchment area of $3848 \mathrm{~km}^{2}$, and a population of 14.5 million people who depend on the water supply from the lake or its outlet, Yodo River. Lake Biwa is one of the world's most ancient lakes and has the most species-rich freshwater ecosystem in Japan, with more than 60 taxa endemic to the Lake Biwa system (Kawanabe et al. 2020). However, Lake Biwa has had problems with proliferated IAS - for example, Micropterus salmoides (largemouth bass) and Lepomis macrochirus (bluegill) -which has resulted in serious degradation of the original biodiversity (Nakai 2020). Since 2013, an intensive attempt has been made to control invasive alien aquatic plants, namely Ludwigia grandiflora ssp. hexapetala ([water primrose] referred to as L. grandiflora, hereinafter), by practicing adaptive governance. This is the reason why we choose it as the case study.

This paper is organized as follows: first, we more precisely discuss the two analytical concepts; next, we provide a brief overview of Japan's invasive species policy framework and explore a case study of adaptive governance in IAS management in Lake Biwa; subsequently, we analyze the findings of the case study and then present the conclusion.

\section{ANALYTICAL FRAMEWORK}

\section{Invasion management}

How should IAS problems be solved? Although this question has been investigated as a theme of invasion management, mainly in invasion ecology, the "guiding principles," an annex in the resolution document of the Sixth Conference of the Parties to the Convention on Biological Diversity (CBD 2002), have often been referred to in this regard. Fifteen principles have been divided into four categories (Table 1).

Table 1. Guiding principles for invasion management (Source: UNEP/CBD/COP/6/20: https://www.cbd.int/doc/decisions/cop-06dec-23-en.pdf)

\begin{tabular}{ll}
\hline \hline A. General & Guiding Principle 1: Precautionary \\
& approach \\
& Guiding Principle 2: Three-stage \\
& hierarchical approach \\
& Guiding Principle 3: Ecosystem approach \\
& Guiding Principle 4: The role of states \\
& Guiding Principle 5: Research and \\
& monitoring \\
& Guiding Principle 6: Education and public \\
& awareness \\
& Guiding Principle 7: Border control and \\
& quarantine measures \\
& Guiding Principle 8: Exchange of \\
& information \\
& Guiding Principle 9: Cooperation, \\
& including capacity-building \\
Guiding Principle 10: Intentional & introduction \\
C. Introduction \\
of species & Guiding Principle 11: Unintentional \\
& introductions \\
D. Mitigation of & Guiding Principle 12: Mitigation of impacts \\
impacts & Guiding Principle 13: Eradication \\
& Guiding Principle 14: Containment \\
& Guiding Principle 15: Control \\
\hline
\end{tabular}

For our analysis, we focus on guiding principle 2, which divides invasion management into three stages and recommends the following in accordance with this prioritization: focus on "prevention" of the invasion first and foremost, "early detection and rapid action" once an invasion has occurred, and "containment and long-term control measures" if eradication is not possible. In general, guiding principle 2 has been accepted by invasion ecologists (Fig. 1).

Fig. 1. Management strategies for invasion management. (Source: Modified Figure 1 from Simberloff et al. 2013)

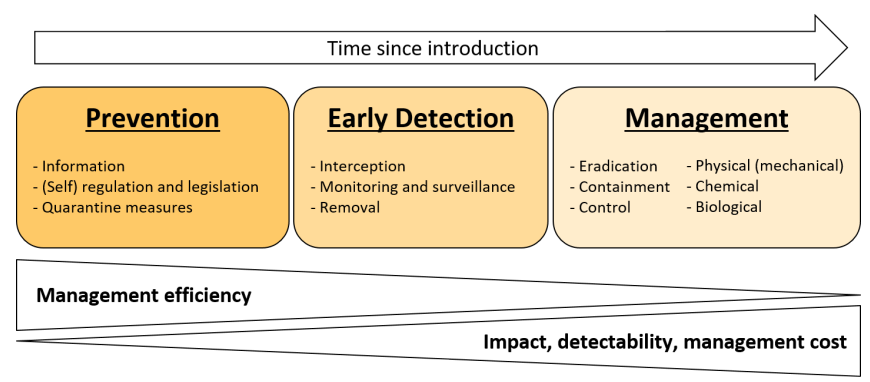

A summary of the essence of this strategy is as follows: First, this concept is deeply related to the nature of harms caused by IAS, which often cause irreversible damage to ecosystems (and 
ecosystem services) or, even if the damage is reversible, require substantial resource inputs for a successful recovery. Therefore, the success or failure of invasion management when conserving biodiversity depends on the ability to prevent control factors that cause the damage rather than reacting to the damage after it occurs. Second, the risk of invasion is related. Because the number of effective measures available at the local level is limited, especially those for preventing invasion, eliminating the risk is impossible. To minimize such risk effectively, measures should be implemented in the multilayered, prioritized manner recommended by this strategy.

Nevertheless, the elements of invasion management have been proposed by invasion ecologists (and some practitioners). By contrast, social or institutional conditions that make invasion management possible remain unclarified; thus, we attempt to clarify them.

\section{Adaptive governance}

In recent years, there has been growing metaresearch on adaptive governance, another analytical concept of this paper, and the essence has been well summarized (Plummer et al. 2013, Chaffin et al. 2014, Karpouzoglou et al. 2016, Steelman 2016, Cleaver and Whaley 2018, Sharma-Wallace et al. 2018). We discuss the following issues, in line with our research objective.

First, adaptive governance assumes a flexible learning-by-doing governing process in social-ecological complexity and uncertainty, as the word "adaptive" indicates. Adaptive governance is rooted in the idea of adaptive management (Holling 1978, Walters 1986), which emphasizes integrating ecosystem dynamics with management structures, fostering experimentation in policy design, and anticipating surprise as a tool for learning (Karpouzoglou et al. 2016). Subsequently, the term "adaptive governance" emerged to expand the focus from the management of ecosystems to addressing the complexity of "broader social contexts" within which people make decisions and share power (Karpouzoglou et al. 2016).

Second, although scientific knowledge occupies a crucial position in adaptive governance, it has sometimes been presented as the antithesis of scientific management (Brunner and Steelman 2005, Brunner and Lynch 2010): scientific management works only if scientific reductionism is prevailing, problems in management are mainly technical, or the decision-making structure is not complicated. In summary, a difference between adaptive governance and scientific management is how scientific knowledge is collected and who uses it.

Third, the meaning of the word "governance" in adaptive governance must be defined. The concept of governance has been investigated in various fields of social science since the 1980s and 1990s, with a growing notion that governing structures and processes gradually change worldwide (e.g., Bevir 2009, Ansell and Torfing 2016). Until those two decades, the most traditional and dominant means of steering society when attempting to achieve common goals was state-centric authoritative governing with formal, hierarchical, and bureaucratic command-andcontrol governmental systems ("governing by government"). Simultaneously, another style of governing, now described as governance, gradually emerged. This style is related to sociopolitical situations in which there is a greater interdependence between government and society, a plural and polycentric governing structure, and a networking interactive process between the government and private and civil society actors and between the local, national, and global levels ("governing by governance").

Therefore, governance generally relates to actors' relationships (horizontal axis) and/or spatial relationships (vertical axis). Notably, adaptive governance also focuses on the time axis. The existence of the aforementioned three stages of invasion management may suggest the necessity for an adaptive governance approach that has a time axis perspective.

Fourth, the type of horizontal relationship between various stakeholders necessary for adaptive governance at the local level has not been well identified. Thus, there are challenges in the operationalization of adaptive governance caused by a lack of understanding of the mechanisms, preparation, and frameworks necessary for the transition to adaptive governance in practice, as well as by limited knowledge of the barriers within institutions and regulatory frameworks to successfully plan and implement adaptive governance frameworks (Sharma-Wallace et al. 2018).

Fifth, the theme of "government in adaptive governance" should also be explored regarding the operationalization of adaptive governance, which has been understudied in adaptive governance research. Discussions concerning "government and governance" can be referred to here and have been presented in social scientific governance studies (e.g., Rhodes 1996, Peters and Pierre 1998, Jordan et al. 2005). In the early era of governance studies, there was an increasing, prevailing recognition of a governing system by using a "from government to governance" analogy in descriptive and/or normative claims (and some advocated "governance without government" at the extreme), which implied the existence of a rigid government-governance dichotomy. Regarding our research object, however, the role and function of government in governance should be further clarified because governments are responsible for IAS management in many countries and situations.

\section{CASE STUDY: INVASIVE ALIEN AQUATIC PLANT MANAGEMENT IN LAKE BIWA}

Japan's invasive species policy framework

Before discussing IAS management practice in Lake Biwa, we provide a brief overview of Japan's invasive species policy framework. The most fundamental policy is the Invasive Alien Species Act, enacted in 2004: its purpose is to "ensure biological diversity," "protect human life and body," and provide "sound development of agriculture, forestry, and fisheries," to designate, regulate, and control "Specified Invasive Alien Species." In addition, the National Biodiversity Strategy of Japan includes invasion management as one of its national targets. Based on these policies, two frameworks, "The Basic Policy for Preventing Damage to Specified IAS" and "The Action Plan for Preventing Damage to Alien Species," have been created; the latter framework requires the following from local governments:

- formulate regional biodiversity strategies for conserving local biodiversity and the sustainable use of its components. Based on these strategies, comprehensive measures against IAS should be promoted by local governments; for example, enacting ordinances or recording the types of IAS by clarifying priority control targets in the region; 
- raise awareness about the IAS that damage local ecosystems, in accordance with the natural and social conditions of the region, and monitor IAS for the purpose of early detection, control, and data collection by experts and citizens to prevent new IAS from damaging local ecosystems;

- in cooperation with surrounding local governments, conduct urgent eradication of IAS that have initially invaded the area to preserve local biodiversity and ensure the local residents' security and property, as well as systematic activities to effectively control IAS that have already established themselves and caused significant damage; and

- foster human resources, for example, by providing training to the individuals who conduct the eradication, to maintain and further develop IAS eradication because most of the eradication of IAS in Japan requires the active involvement of the community in which the species is established.

Thus, what enables adaptive governance in invasion management to address these issues? What are the social and institutional barriers that hinder the emergence and functioning of such adaptive governance? We attempt to answer these questions.

\section{Lake Biwa and Ludwigia grandiflora}

L. grandiflora is an aquatic plant that is native to South America and southern North America and is a typical example of an IAS that is causing problems such as the exclusion of native plants, habitat degradation for fish and benthic animals, obstruction of fish migration, and obstruction of vessel navigation and fisheries (Nakai 2020) (Fig. 2).

Fig. 2. Ludwigia grandiflora in Lake Biwa, and its control. (Photos: Katsuki Nakai)
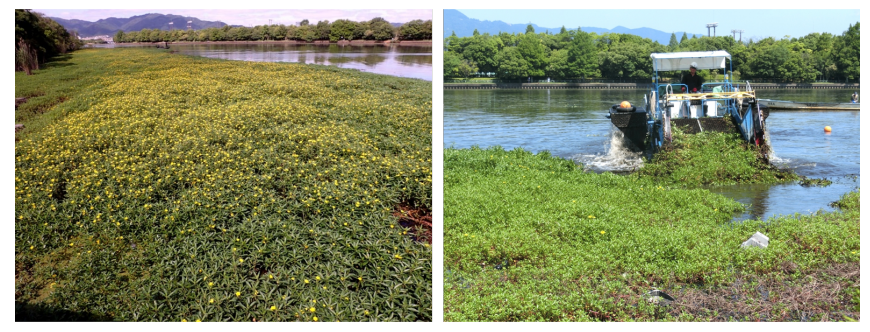

L. grandiflora has characteristics that make it an IAS. First, this perennial herb grows rapidly, can overwinter despite its tropical and subtropical origin, and has a community size that expands annually. Second, L. grandiflora has a vegetative propagation habit such that it grows as a new individual when small fragments of stems and leaves take root; it also exhibits a seed-breeding habit. Due to this flexibility in reproduction, L. grandiflora has a remarkable ability to expand its distribution. Third, ecologically, this perennial herb is amphibious, not purely aquatic; a single individual will extend its stems and leaves not only along the water surface but also on the ground, and if an individual starts growing on the land, it can live for many years, although it apparently grows more rapidly and densely in water.

Because of these features, the spread of L. grandiflora is aggravated by meteorological factors such as rising water levels after heavy rainfall and strong waves caused by typhoons, which generate "terrestrial" individuals that have difficult-to-remove roots that penetrate into the hardened land. Therefore, to effectively control the growth area and distribution, we expect that the introduction of efficient, large-scale suppression methods and the establishment of a widespread vigilance system are necessary.

Effective control of L. grandiflora is difficult for the following reasons (e.g., Mineta et al. 2020). First, this plant spreads stems and leaves along the surface of the water and grows densely under the water surface (up to $40 \mathrm{~kg} / \mathrm{m}^{2}$ ); thus, carrying the plants removed from the water directly to the land or lifting them up onto a boat for transportation is difficult. In addition, the size of the community often exceeds several thousand square meters; thus, specialized machines with strong physical power, such as a special water-grass cutter (e.g., harvester) or construction equipment (e.g., swing yarder), are required to control the communities growing in a large population.

Second, although these specialized machines can collect a large amount of $L$. grandiflora, it is essential to conduct careful manual removal from the areas where the older, heavier stems are growing along and rooting into the bottom substratum because they neither float nor are easy to collect. In addition, stems and leaves within the water are easily broken, and fragmented leaves and stems easily drift and produce new plants. Therefore, for effective control, it is important to reduce the number of remaining unfloating stems and drifting plant fragments as much as possible. In particular, it is recommended that the water surface of the work area be enclosed with a floating fence, and floating plant fragments should be carefully collected by a small boat. Moreover, regular patrols and monitoring are necessary to prevent the regeneration of the community from the remaining stems and roots on newly drifted fragments, even after the intensive removal.

Third, even removals based on these considerations are technically difficult when attempting to effectively remove communities that are deeply rooted in the terrestrial part of a masonry revetment or that are intermingled with other emergent plants such as reeds (Phragmites australis) and knotgrass (Paspalum distichum var. indutum). Although researchers have begun to explore the possibility of using chemical treatment - for example, an application used in the United Kingdom (Kamigawara et al. 2020) — careful evaluation procedures are necessary because some of the chemicals, such as herbicides, contain components that harm ecosystems (especially aquatic plants and phytoplankton) and human health.

Fourth, proper treatment and disposal of the large amount of removed plants are difficult. Although composting is a promising method for the disposal of many mown plants, L. grandiflora is amphibious, desiccation-resistant, and has a high potential for regeneration from plant fragments, such as small pieces of stems and leaves, and germination from seeds; thus, composting poses the risk of regeneration. Therefore, incineration or burial is the safe disposal method.

Fifth, additional limitations must be resolved. Most notably, in Japan, mown plants are legally treated as "general waste" without commercial value, and municipalities are responsible for accepting and processing disposal, including "general waste." This policy indicates that cooperation with municipal governments is indispensable to the smooth promotion of control. 
Sixth, for disposal by incineration, L. grandiflora removed from aquatic habitats must be sufficiently dried, and land must be secured for temporary storage. Additionally, during the storage for drying, the roots must be prevented from growing into the ground. Thus, if the ground is unpaved, control measures must be undertaken; for example, laying sheets or pallets on the ground and covering the entire area with sheets to prevent dried stems and leaves from being scattered by the wind or getting wet from the rain.

In and around Lake Biwa, L. grandiflora was first identified in Akanoi Bay, located on the eastern coast of the southern basin of the lake, in December 2009 (Mr. Minoru Kuribayasi, personal communication); however, the invasion might have begun before 2007 (Hieda et al. 2016). Before the 2010s, L. grandiflora was found in three other prefectures (Hyogo, Wakayama, and Kagoshima), which are at least 30 miles from each other: the populations in Hyogo and Wakayama prefectures are the $L$. grandiflora subsp. grandiflora, and those in Shiga and Wakayama are the L. grandiflora subsp. hexapetala. (Hieda et al. 2020). Both subspecies of L. grandiflora are an ornamental aquatic plant with large, brightly colored flowers, and are presumed to have been imported from abroad through several routes.

In 2004, when the Invasive Alien Species Act was enacted, there was no recognition of $L$. grandiflora's feralization in the wild in Japan, and there was little information on its invasiveness. In response to its dramatic increase and severe ecological impacts in Lake Biwa, L. grandiflora was designated as a "specified Invasive Alien Species" in June 2014, and its rearing, cultivation, storage, and transportation were strictly regulated, accordingly.

In Lake Biwa, the range of $L$. grandiflora rapidly expanded to cover most of the southern basin area and gradually spread to the northern basin area (Fig. 3), which suggests that its distribution expanded through the natural behavior of birds and/ or unconfirmed human activities. The distribution range gradually expanded downstream from Lake Biwa, beyond the border of Shiga prefecture, because the water of Lake Biwa flows down and through its only outlet, the Yodo River, which runs through Kyoto and Osaka prefectures and the Lake Biwa Canal, and supplies water to Kyoto city.

\section{Invasive alien aquatic plant management in Lake Biwa ${ }^{[2]}$}

After the enactment of the Invasive Alien Species Act in 2007, the naturalization of Specified Invasive Alien Species such as the Senegal tea plant (Gymnocoronis spilanthoides) and alligatorweed (Alternanthera philoxeroides) was confirmed in Lake Biwa. Immediately after that confirmation, volunteer experts implemented activities to eradicate those plants, and subsequently, the Shiga prefectural government followed with eradication efforts. The distribution of $L$. grandiflora spread dramatically after its first confirmation in 2009; thus, another volunteer attempt was conducted to manage the plant's growing population. The volunteer experts invited a leading aquatic botanist (Professor Dr. Y. Kadono) to observe the established large-scale community of $L$. grandiflora. He strongly recommended to the governor of Shiga prefecture that intensive efforts be implemented to eradicate $L$. grandiflora. In response, the Shiga prefectural government conducted intensive removal of L. grandiflora during its alien species monitoring project in 2013, and the necessity of large-scale efforts for effective control of the plant was strongly recognized.
Fig. 3. Total vegetation area of Ludwigia grandiflora in Lake Biwa. (Data: Lake Biwa Special Council for Invasive Aquatic Plants, Shiga prefecture)

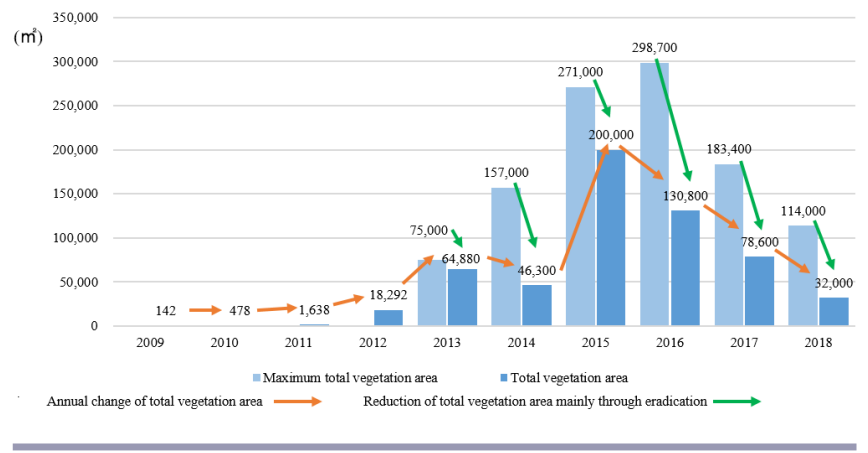

In 2014, the Lake Biwa Special Council for Invasive Aquatic Plants was established by the Shiga prefectural government, with subsidies from the Ministry of the Environment. The council's purpose is "to contribute to the conservation and regeneration of biodiversity in Lake Biwa by promoting measures against invasive aquatic plants" (Article 3 of the council's code). The council members are from several divisions of the Shiga prefectural government, municipalities along the Lake Biwa shore, civil organizations, and fisheries cooperatives. The council conducts most of the project activities for controlling invasive alien aquatic plants, which are financed by the prefectural government and subsidies from the Ministry of the Environment; thus, nonprefectural members incur no financial burden.

In terms of our research objective, what is most essential is the role of each council member. First, most of the IAS plant communities are distributed in Lake Biwa, satellite lakes, and lower reaches of inflowing rivers, which are managed mostly by the Shiga prefecture government. Thus, the Shiga prefecture government plays a major role in the proper control of IAS plants, not only in the areas under its management but also in the other areas where the IAS plant communities often grow so densely that local non-prefectural members cannot eliminate them by their own efforts. The non-prefectural members also conduct their activities at the local level, and municipalities gather information on new findings from residents. The council members in equivalent positions cooperate to address IAS problems and propose initiatives to accomplish those objectives.

Second, the Nature Conservation Division of the prefectural government is the secretariat of the council, and one of the staff in charge is a curator (ecologist) of the Lake Biwa Museum. This enables the secretariat to link policy and science, and to function as a hub for a network of researchers.

Most of the prefectural government's measures implemented against $L$. grandiflora are in the form of the council's projects, described in detail by focusing on the council's annual expenditure (Fig. 4).

Since the inception of the council's projects in 2014, most of the expenditures have been for the treatment of a substantial amount of collected plants; other expenditures have included the removal of the plants from the wild, storage of plants for drying and 
Fig. 4. Total annual expenditure by the Lake Biwa Special Council for Invasive Aquatic Plants (thousand Japanese yen). (Data: Lake Biwa Special Council for Invasive Aquatic Plants, Shiga prefecture)

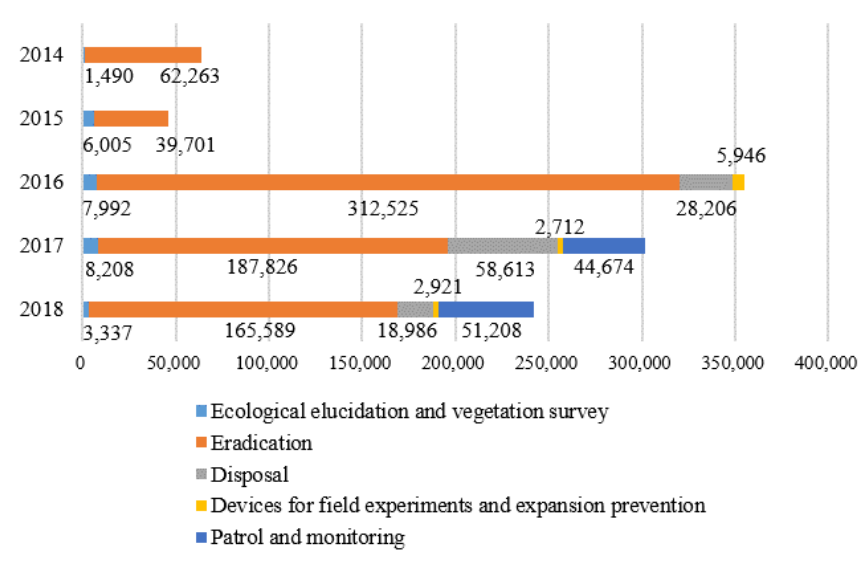

reducing weight, and disposal of plants through incineration. Heavy machinery is used for large-scale removal of overgrown communities. In the beginning, the ability of L. grandiflora to regenerate from the remaining plant bodies, and the presence of numerous small-sized populations, especially on the western shore of the southern basin - both of which are the major cause of the unexpected "rebound" after the initial intensive removal efforts -were not properly expected. This increasing trend, with an uncertain background, continued until 2016, and was often accompanied by IAS management. In the process of the project's operation, the members had to respond flexibly to various unexpected situations, such as rapid regeneration of communities from plant fragments remaining or drifted in the removal sites, sudden appearance in the sites without the establishment of large and/or long-lasting communities such as the northern basin area, and unexpected migration in high-elevation or upstream directions because of typhoons. These situations required additional efforts for the project's operation, with increasing frequency, supported by supplementary budgets. In response to the increasing scale of the project, and the accumulated information obtained through this process, the areas were classified into several categories according to the risk priorities, such as further dispersal, obstacles to cruising and fisheries, and invasion into areas to be protected in subsequent years.

Notably, "devices for field experiments and expansion prevention" and "patrol and monitoring" have been added since 2017 (Fig. 4). As the growth area decreases, efforts are expanded to prevent the next development, such as the use of containment technology (anti-diffusion nets and shade sheets), ecological surveys (measurement of dissolved oxygen in the water under the community), and early detection, especially in unexpected areas.

Moreover, though not directly expressed as an expenditure item, the prefectural government has provided various supports for council members; for example, it provides necessary equipment (e.g., long boots, large blue tarps, mesh bags for collection), coordinates with municipal governments, and complies with regulations under the IAS Act and the Waste Disposal and Public Cleansing Acts.

\section{ANALYSIS AND DISCUSSION}

Adaptive governance as three learning processes

The analysis suggests that whether learning processes are properly equipped by local environmental governance is critical for adaptive governance. The word "learning" in the prior sentence comprises three elements. The first element is the production and sharing of scientific knowledge. In this case, the scientific knowledge of and control technology for L. grandiflora are produced and shared through activities: policy preparation, implementation, and evaluation. For example, the council has conducted annual intensive research on this plant's distribution on the lake shore and surrounding waters, including satellite lakes and creeks and rivers close to the lake, and the distribution map has been updated, which provides fundamental information for setting priority areas for the project. Another example is that the council conducts field experiments such as using nets for diffusion prevention and using shade sheets for proliferation control, through which the ecology of L. grandiflora in Lake Biwa is gradually clarified.

The second element is a type of social learning, which is sometimes elaborated in the natural resource management context, and is defined as "a change in understanding that goes beyond the individual to become situated within wider social units or communities of practice through social interactions between actors within social networks" (Reed et al. 2010). The reason why social learning is essential for IAS management has been explained. For example, IAS problems and the resulting ecological disturbances can propagate across jurisdictions, and management strategies propagate across social networks of managers; social learning can compensate for the weakness of individual learning and in the case that outcomes are difficult to observe or are delayed over long periods, as is often the case with IAS management (Baggio and Hillis 2018). Research has also shown that processes that support social learning involve sustained interaction between stakeholders, on-going deliberation, and the sharing of knowledge in a trusting environment (Cundill and Rodela 2012), which conforms to our case study. The case study indicates that local environmental governance could foster communication between various actors if it is designed to create an interactive relationship. Notably, the council is also a forum for the prefectural government to explain new findings on the distribution and growth status of target species and other urgent concerns, and for the members of the prefectural government to consult with each other to facilitate the operation and implementation of the project.

Third, organizational learning, an idea in organizational theory, is also essential for effective adaptive governance. Although it has multiple definitions, it contains changes in the organization's knowledge through the common organizational experiences and process change through which an organization produces new knowledge and has the potential to influence cognitions, theoryin-use, behaviors, and performances of the organization (e.g., Fiol and Lyles 1985, Huber 1991, Argyris and Schön 1996, EasterbySmith and Lyles 2003, Argote and Miron-Spector 2011). In the 
section Transition toward precautionary actions, in the context of our case study, we discuss the function of organizational learning or how organizational learning induces effective adaptive governance.

\section{Government in adaptive governance: primus inter pares in interactive governance under social-ecological complexities and uncertainties}

The case study indicates the following lessons concerning the role and function of government in making adaptive governance work: first, government in adaptive governance could be expressed as a primus inter pares ("first among equals"), a metaphor sometimes used in governance theories. This idea is largely applicable to the case where interactive governance is possible even when the government initiates a governing process. Moreover, this implies that the government-governance dichotomy is also inappropriate in adaptive governance debates.

Second, we identified in the case study that non-prefectural members do not petition the prefectural government to remove IAS, and the prefectural government does not mobilize nonprefectural members for IAS removal. This finding implies that such an interactive governing structure would be fundamental for addressing social-ecological complexities and uncertainties. In this case, unexpected incidents such as IAS re-proliferation after intensive removal efforts, IAS diffusion by typhoons, and shortage of drying spaces and incinerators were expeditiously addressed by each member, with flexible supports provided by the government.

\section{Transition toward precautionary actions for invasive alien species fostered by interactive governing structure and organizational learning}

In the prior section, we discussed that the success or failure of invasion management depends on the ability to take precautionary actions against IAS problems rather than reacting to the damage after it occurs, and that many practitioners, in general, have often had difficulty in doing that. By contrast, since 2017 , the council has succeeded in a transition to "early detection" (Fig. 1). Why is there a difference? Our exploration suggests the following two factors.

First, the difference is at least partly ascribed to an interactive feature of the governing structure, in terms of the relationship between government and non-government actors, and between non-government actors. In Lake Biwa, demand is emerging for a careful, precise response to the relatively small communities of L. grandiflora growing on masonry revetment, which are technically difficult to remove, and on lakeshores. A local environmental governance system such as the council, where various actors communicate and cooperate, would help make the "early detection" strategy easier (Fig, 1), to some extent. In this case, for example, some council members, government, or nongovernment actors regularly monitor and visit the site to assess the necessity for emergency measures. ${ }^{[3]}$ If the relationship between actors is vertical, organized in line with the principle of petition or mobilization, no such voluntary initiatives are implemented.

An interactive governing structure has another potential benefit; in the case of adaptive governance, it contributes to raising awareness about the risks of IAS. A local environmental governance system in which various actors are involved and interactive relationships between them are established can easily gather, accumulate, and share scientific knowledge and related information. This feature would facilitate outreach efforts to the local community and the general public to raise awareness about IAS or to demonstrate the importance of "early detection" and "prevention" strategies (Fig. 1).

Second, organizational learning can help make precautionary measures possible. In organizational theory, organizational learning is often divided into two types, which are expressed as, for example, "single-loop and double-loop" (Argyris and Schön 1996), "lower-level and higher-level" (Fiol and Lyles 1985), or "exploitation and exploration" (March 1991). Generally, the former is composed of inferences from history, which guides the organization's routine and does not change the value system of action and organization. The competency trap caused by conformity bias easily occurs in this situation, especially when certain achievements blind the eyes to the procedural inferiority. This structure explains, at least partly, why IAS management often tends to concentrate on removal, not precautionary measures.

By contrast, the latter is a heuristic one with a change of the value system, relevant in coping with uncertainty when managing complex systems. The case study suggests that the council has been avoiding the competency trap by accumulating information from monitoring, which enables the members to address unexpected events and results.

\section{CONCLUSIONS}

How can IAS management in freshwater ecosystems (and further, biodiversity conservation) enhance policy effectiveness and outcomes under such situations where a government is no longer the sole actor in environmental governance; high social-ecological complexity and uncertainty should be considered; precautionary measures are superior to doing it in a symptomatic treatment, which does not fight against causes; and governing structure and process should be interactive? We have attempted to explore this question through the lens of invasion management and adaptive governance, and a case study of invasive alien aquatic plant management in Lake Biwa, Japan.

Our analysis has provided valuable practical lessons and theoretical implications, and we have advanced the understanding of adaptive governance in Japan and Asia, the research on which has been relatively poorer than that of European countries and the United States.

${ }^{[1]}$ The various definitions of IAS (e.g., Heger et al. 2013) depend partly on whether this topic is explored academically or practically. Notably, a discussion of the details of the definitions is beyond the scope of this paper; therefore, we use the following definition: "an alien species whose introduction and/or spread threatens biological diversity" (CBD 2002).

${ }^{[2]}$ This section is based largely on general meeting materials of the Lake Biwa Special Council for Invasive Aquatic Plants council.

[3] In ecological field studies, volunteer engagement has been observed in scientific research such as ours, and has involved gathering information or monitoring at broad special and temporal scales, which is called citizen science (e.g., Cooper et al. 2007, Bonney et al. 2009, Dickinson et al. 2012). 
Responses to this article can be read online at:

https://www.ecologyandsociety.org/issues/responses. php/12352

\section{Acknowledgments:}

The authors are very grateful for the members of the Nature Environment Conservation Division, Department of Lake Biwa and Environment, Shiga Prefectural Government, who provided us with relevant information and knowledge. In addition, the authors thank participants in the poster presentation at the XVIIth Biennial IASCConference in Lima, Peru for their advice. This work was supported by the Japan Society for the Promotion of Science (JSPS) KAKENHI Grant Numbers JP16H03008 and JP18K11765. The authors would also like to thank Enago (www.enago.jp) for the English language review.

\section{Data Availability:}

Datalcode sharing not applicable.

\section{LITERATURE CITED}

Ansell, C., and J. Torfing, editors. 2016. Handbook on theories of governance. Edward Elgar Publishing, Cheltenham, UK. https:// doi.org/10.4337/9781782548508

Argote, L., and E. Miron-Spector. 2011. Organizational learning: from experience to knowledge. Organization Science 22 (5):1123-1137. https://doi.org/10.1287/orsc.1100.0621

Argyris, C., and D.A. Schön. 1996. Organizational learning II: theory, method and practice. Addison-Wesley, Reading, Massachusetts, USA.

Armitage, D., R. de Loë, and R. Plummer. 2012. Environmental governance and its implications for conservation practice. Conservation Letters 5(4):245-255. https://doi.org/10.1111/ j.1755-263X.2012.00238.X

Baggio, J. A., and V. Hillis. 2018. Managing ecological disturbances: learning and the structure of social-ecological networks. Environmental Modelling \& Software 109:32-40. https:// doi.org/10.1016/j.envsoft.2018.08.002

Bevir, M. 2009. Key concepts in governance. SAGE Publications Ltd, London, UK.

Bonney, R., C. B. Cooper, J. Dickinson, S. Kelling, T. Phillips, K. V. Rosenberg, and J. Shirk. 2009. Citizen science: a developing tool for expanding science knowledge and scientific literacy. BioScience 59(11):977-984. https://doi.org/10.1525/bio.2009.59.11.9

Brunner, R. D., and A. H. Lynch. 2010. Adaptive governance and climate change. American Meteorological Society, Boston, Massachusetts, USA. https://doi.org/10.1007/978-1-935704-01-0

Brunner, R. D. and T. A. Steelman. 2005. Beyond scientific management. Pages 1-46 in R. D. Brunner, T. A. Steelman, L. Coe-Juell, C. M. Cromley, C. E. Edwards, and D. W. Tucker. Adaptive management: integrating science, policy and decision making. Columbia University Press, New York, USA.
Brunner, R. D., T. A. Steelman, L. Coe-Juell, C. M. Cromley, C. E. Edwards, and D. W. Tucker. 2005. Adaptive governance: integrating science, policy, and decision making. Columbia University Press, New York, USA.

Chaffin, B. C., A. S. Garmestani, D. G. Angeler, D. L. Herrmann, C. A. Stow, M. Nyström, J. Sendzimir, M. E. Hopton, J. Kolasa, and C. R. Allen. 2016. Biological invasions, ecological resilience and adaptive governance. Journal of Environmental Management 183:399-407. https://doi.org/10.1016/j.jenvman.2016.04.040

Chaffin, B. C., H. Gosnell, and B. A. Cosens. 2014. A decade of adaptive governance scholarship: synthesis and future directions. Ecology and Society 19(3):56. http://dx.doi.org/10.5751/ ES-06824-190356

Cleaver, F., and L. Whaley. 2018. Understanding process, power, and meaning in adaptive governance: a critical institutional reading. Ecology and Society 23(2):49. https://doi.org/10.5751/ ES-10212-230249

Convention on Biological Diversity (CBD). 2002. Guiding principles for the prevention, introduction and mitigation of impacts of alien species that threaten ecosystems, habitats or species; annex to COP 6 decision VI/23 of the Convention on Biological Diversity.

Cooper, C. B., J. Dickinson, T. Phillips, and R. Bonney. 2007. Citizen science as a tool for conservation in residential ecosystems. Ecology and Society 12(2):11. https://doi.org/10.5751/ES-02197-120211

Cundill, G., and R. Rodela. 2012. A review of assertions about the processes and outcomes of social learning in natural resource management. Journal of Environmental Management 113:7-14. http://dx.doi.org/10.1016/j.jenvman.2012.08.021

Davis, E., J. M. Caffrey, N. E. Coughlan, J. T. A. Dick, and F. E. Lucy. 2018. Communications, outreach and citizen science: spreading the word about invasive alien species. Management of Biological Invasions 9(4):515-525. https://doi.org/10.3391/ mbi.2018.9.4.14

Dickinson, J., J. Shirk, D. Bonter, R. Bonney, R. L. Crain, J. Martin, T. Phillips, and K. Purcell. 2012. The current state of citizen science as a tool for ecological research and public engagement. Frontiers in Ecology and the Environment 10 (6):291-297. https://doi.org/10.1890/110236

Dietz, T., E. Ostrom, and P. C. Stern. 2003. The struggle to govern the commons. Science 302:1907-1912. http://dx.doi.org/10.1126/ science. 1091015

Easterby-Smith, M., and M. A. Lyles, editors. 2003. The Blackwell handbook of organizational learning \& knowledge management. Blackwell Publishers, Malden, assachusetts, USA and Oxford, UK.

Fiol, C. M., and M. A. Lyles. 1985. Organizational learning. Academy of Management Review 10(4):803-813. https://doi. org/10.2307/258048

Folke, C., T. Hahn, P. Olsson, and J. Norberg. 2005. Adaptive governance of social-ecological systems. Annual Review of Environment and Resources 30(1):441-473. http://dx.doi. org/10.1146/annurev.energy.30.050504.144511 
Francis, R. A., editor. 2012. A handbook of global freshwater invasive species. Routledge, London, UK. https://doi. org/10.4324/9780203127230

Heger, T., W.-C. Saul, and L. Trepl. 2013. What biological invasions 'are' is a matter of perspective. Journal for Nature Conservation 21(2):93-96. https://doi.org/10.1016/j.jnc.2012.11.002

Hieda, S., Y. Kaneko, M. Nakagawa, and N. Noma. 2016. Biological classification and life history characteristics of an invasive aquatic plant, Ludwigia grandiflora. Poster presentation at 63rd Annual Meeting of the Ecological Society of Japan, Sendai, Japan, 22 March 2016. https://www.esj.ne.jp/meeting/ abst/63/P1-405.html

Hieda, S., Y. Kaneko, M. Nakagawa, and N. Noma. 2020. Ludwigia grandiflora (Michx.) Greuter \& Burdet subsp. hexapetala (Hook. \& Arn.) G. L. Nesom \& Kartesz, an invasive aquatic plant in Lake Biwa, the largest lake in Japan. Acta Phytotaxonomica Geobotanica 71(1):65-71. http://doi.org/10.18942/ apg.201911

Holling, C. S. 1978. Adaptive environmental assessment and management. John Wiley and Sons, Chichester, UK.

Huber, G. P. 1991. Organizational learning: the contributing processes and the literatures. Organization Science 2(1):88-115. https://doi.org/10.1287/orsc.2.1.88

Jordan, A., R. K. W. Wurzel, and A. Zito. 2005. The rise of 'new' policy instruments in comparative perspective: Has governance eclipsed government? Political Studies 53(3):477-496. https://doi. org/10.1111/j.1467-9248.2005.00540.x

Kamigawara, K. 2016. Rapid response thesis and policy process in managing invasive alien species: case studies on amphibian alien plants control, Papers on Environmental Information Science 30:133-138. [title translated from Japanese] https://doi. org/10.11492/ceispapers.ceis30.0_133

Kamigawara, K., K. Nakai, N. Noma, S. Hieda, E. Sarat, A. Dutartre, T. Renals. R. Bullock, J. Haury, B. Bottner, and J-P. Damien. 2020. What kind of legislation can contribute to on-site management?: Comparative case studies on legislative developments in managing aquatic invasive alien plants in France, England, and Japan. Journal of International Wildlife Law \& Policy 23(2):83-108. https://doi.org/10.1080/13880292.2020.1788778

Karpouzoglou, T., A. Dewulf, and J. Clark. 2016. Advancing adaptive governance of social-ecological systems through theoretical multiplicity. Environmental Science \& Policy 57:1-9. https://doi.org/10.1016/j.envsci.2015.11.011

Kawanabe, H., M. Nishino, and M. Maehata, editors. 2020. Lake Biwa: interactions between nature and people. Second edition. Springer Nature Switzerland, Cham, Switzerland. https://doi. org/10.1007/978-3-030-16969-5

Lemos, M. C. and A. Agrawal. 2006. Environmental governance. Annual Review of Environment and Resources 31:297-325. https:// doi.org/10.1146/annurev.energy.31.042605.135621

March, J. G. 1991. Exploration and exploitation in organizational learning. Organization Science 2(1):71-87. https://doi.org/10.1287/ orsc. 2.1 .71
Mineta, T., K. Nakai, N. Hayashi, and H. Marui. 2020. Control and issue for invasive alien aquatic plants affecting farming and water use. Water, Land and Environmental Engineering 88 (11):887-891. [title translated from Japanese] [online] URL: $\underline{\text { http:// }}$ www.jsidre.or.jp/wordpress/wp-content/uploads/2020/10/88-11_p003-007. pdf

Nakai, K. 2009. Perspective for alien species problems in inland waters. Japanese Journal of Limnology 70(3):277-280. [title translated from Japanese] https://doi.org/10.3739/rikusui.70.277

Nakai, K. 2020. Countermeasures against invasive alien species: regulations and control. Pages 585-592 in H. Kawanabe, M. Nishin, and M. Maehata, editors. Lake Biwa: interactions between nature and people. Second edition. Springer Nature Switzerland, Cham, Switzerland.

Novoa, A., R. Shackleton, S. Canavan, C. Cybèle, S. J. Davis, K. Dehnen-Schmutz, J. Fried, M. Gaertner, S. Geerts, C. L. Griffiths, H. Kaplan, S. Kumschick, D. C. Le Maitre, G. J. Measey, A. L. Nunes, D. M. Richardson, T. B. Robinson, J. Touza, and J. R. U. Wilson. 2018. A framework for engaging stakeholders on the management of alien species. Journal of Environmental Management 205:286-297. https://doi.org/10.1016/j.jenvman.2017.09.059

Ohno, T. 2018. Understanding diverse trajectories of environmental governance studies: a citation network analysis. Environment Systems and Decisions 39:1-15. https://doi. org/10.1007/s10669-018-9715-4

Peters, B. G., and J. Pierre. 1998. Governance without government? Rethinking public administration. Journal of Public Administration Research and Theory 8(2):223-243. https://doi. org/10.1093/oxfordjournals.jpart.a024379

Plummer, R., D. R. Armitage, and R. C. de Loë. 2013. Adaptive comanagement and its relationship to environmental governance. Ecology and Society 18(1):21. http://dx.doi.org/10.5751/ ES-05383-180121

Reed, M. S., A. C. Evely, G. Cundill, I. Fazey, J. Glass, A. Laing, J. Newig, B. Parrish, C. Prell, C. Raymond, and L. C. Stringer. 2010. What is social learning? Ecology and Society 15(4):r1. https://doi.org/10.5751/ES-03564-1504r01

Rhodes, R. A. W. 1996. The new governance: governing without government. Political Studies 44(4):652-667. https://doi. org/10.1111/j.1467-9248.1996.tb01747.x

Riccardi, A., and H. J. MacIsaac. 2011. Impacts of biological invasions on freshwater ecosystems. Pages 211-224 in D. M. Richardson, editor. Fifty years of invasion ecology: the legacy of Charles Elton. Wiley-Blackwell, Hoboken, New Jersey, USA. https://doi.org/10.1002/9781444329988.ch16

Riccardi, A., M. E. Palmer, and N. D. Yan. 2011. Should biological invasions be managed as natural disasters? Bioscience 61(4):312-317. https://doi.org/10.1525/bio.2011.61.4.11

Secretariat of the Convention on Biological Diversity. 2014. Global biodiversity outlook 4. Montreal, Quebec, Canada. [online] URL: https://www.cbd.int/gbo/gbo4/publication/gbo4en-hr.pdf 
Shackleton, R. T., T. Adriaens, G. Brundu, K. Dehnen-Schmutz, R. A. Estèvez, J. Fried, B. M. H. Larson, S. Liu, H. Marchante, M. C. Moshobane, A. Novoa, M. Reed, and D. M. Richardson. 2019. Stakeholder engagement in the study and management of invasive alien species. Journal of Environmental Management 229:88-101. https://doi.org/10.1016/j.jenvman.2018.04.044

Sharma-Wallace, L., S. J. Velarde, and A. Wreford. 2018. Adaptive governance good practice: show me the evidence! Journal of Environmental Management 222:174-184. https://doi.org/10.1016/ j.jenvman.2018.05.067

Simberloff, D., J.-L. Martin, P. Genovesi, V. Maris, D. A. Wardle, J. Aronson, F. Courchamp, B. Galil, E. García-Berthou, M. Pascal, P. Pysek, R. Sousa, E. Tabacchi, and M. Vilà. 2013. Impacts of biological invasions: what's what and the way forward. Trends in Ecology \& Evolution 28(1):58-66. https://doi. org/10.1016/j.tree.2012.07.013

Steelman, T. 2016. Adaptive governance. Pages 538-550 in C. Ansell and J. Torfing, editors. Handbook on theories of governance. Edward Elgar Publishing, Cheltenham, UK. https://doi. org/10.4337/9781782548508.00056

Walters, C. J. 1986. Adaptive management of renewable resources. Macmillan, New York, USA. 